\title{
Acute haemodynamic effects of felodipine during beta blockade in patients with coronary artery disease
}

\author{
W CULLING, M S M RUTTLEY, D J SHERIDAN \\ From the Department of Cardiology, Welsh National School of Medicine, Cardiff
}

SUMMARY The acute effects of felodipine on left ventricular function and haemodynamics were studied in 11 patients with coronary artery disease. To block reflex sympathetic activation due to peripheral vasodilatation and to avoid effects secondary to changes in heart rate all patients received a standard regimen of beta adrenoceptor blockade and all measurements were made during sinus rhythm and right atrial pacing. At 30 minutes after an oral dose $(0.075 \mathrm{mg} / \mathrm{kg}$ in solution) felodipine plasma concentration were $16.4(3.5) \mathrm{nmol} / \mathrm{l}$. A significant fall in systemic vascular resistance (30\%) and increase in cardiac index (30\%) occurred, whereas pulmonary vascular resistance was unchanged. Felodipine increased left ventricular ejection fraction and mean velocity of circumferential fibre shortening but had no effect on derivates of left ventricular pressure $\left(\mathrm{dP} / \mathrm{dt}\right.$ or $\left.\mathrm{dP} / \mathrm{dt}^{-1}\right)$ during sinus rhythm or pacing. Thus at the dosage used felodipine was a potent dilator of systemic arterioles but had no direct effect on left ventricular function.

Felodipine is a new dihydropyridine compound, which has been claimed (in vitro) to be a potent vasodilator with less cardiodepressive effect than other calcium antagonists. ${ }^{1}$ Its mechanism of action in relaxing vascular smooth muscle is unclear, although it has been suggested that it inhibits the activation, by calcium ions, of intracellular calmodulin ${ }^{2}$ and only at high concentration does it act as a slow calcium channel blocker. A non-invasive study ${ }^{3}$ of young healthy men confirmed its action as a vasodilator in man; there are, however, no direct measurements available of its effect on left ventricular function. In this study therefore we measured the systemic and left ventricular haemodynamic effects of felodipine in patients undergoing cardiac catheterisation for investigation of chest pain. We and others ${ }^{45}$ have previously shown that control of heart rate and blockade of reflex sympathetic activation is essential to avoid masking direct negative inotropic actions of peripheral vasodilators. ${ }^{6-8}$ For this reason measurements were carried out at rest and during atrial pacing in patients receiving beta blocking agents.

Requests for reprints to: Dr D J Sheridan, Department of Cardiology, Welsh National School of Medicine, Heath Park, Cardiff CF4 4XN.

Accepted for publication 24 May 1984

\section{Patients and methods}

Eleven men aged 34-62 (mean 49.6) years were entered into the study. All patients had classical angina pectoris and positive exercise tests (Bruce protocol) and were about to undergo cardiac catheterisation. Coronary arteriography at the end of each study showed that all had coronary artery disease (four single vessel disease, six two vessel disease, and one left main stem disease). Seven of the 11 had had a previous myocardial infarct (more than three months before the study), but none had congestive heart failure, cardiac conduction abnormalities, valvular heart disease, or biochemical evidence of hepatic or renal disease. Medical treatment at entry to the study consisted of a beta adrenoreceptor blocker in nine patients, long acting oral nitrate in eight, calcium antagonists in four, and other vasodilators in two. Nitrates, vasodilators, and beta adrenoceptor blockers were discontinued for at least 24 hours before the study, and to standardise beta adrenoreceptor blocking treatment all patients received atenolol $100 \mathrm{mg}$ six hourly for the same period.

The patients were studied after an overnight fast and premedication with diazepam $(10 \mathrm{mg})$ orally. Heart rate was measured from electrocardiograms (mean of six beats). A Swan-Ganz thermodilution catheter was positioned in the pulmonary artery for 
pressure recording, blood sampling, and estimation of cardiac output (mean of three readings). A bipolar pacing electrode was positioned in the right atrium. Arterial pressure was recorded from the sidearm of a sheath positioned in the femoral artery. A pressure tip catheter (Millar Instruments) was passed via the sheath to the left ventricle for high fidelity recordings; derivatives of left ventricular pressure $(\mathrm{dP} / \mathrm{dt}$ and $\mathrm{dP} / \mathrm{dt}^{-1}$ ) were obtained using analogue circuitry (Siemens). Stroke volume, ejection fraction, ${ }^{9}$ and mean velocity of circumferential fibre shortening ${ }^{10}$ were derived from left ventricular angiograms.

Control haemodynamic measurements were taken during sinus rhythm and during right atrial pacing at 100 beats/min, and a baseline left ventricular angiogram was then performed ( $40 \mathrm{ml}$ Hexabrix at $12 \mathrm{ml} / \mathrm{s}$ ) during pacing. Repeat measurements including left ventriculography were obtained 30 minutes after felodipine $0.075 \mathrm{mg} / \mathrm{kg}$ had been given orally. Blood samples for the estimation of plasma felodipine concentrations were taken during the baseline recordings, at 10,20 , and 30 minutes after the oral dose, and after the second left ventricular angiogram. To assess the haemodynamic effects of the contrast material used separate studies were carried out in a further seven patients who underwent the initial left ventricular angiogram but received no drug, after which haemodynamic measurements were made in the usual way. Results are expressed as mean (SE) and were analysed using Student's $t$ test, a probability value of 0.05 being taken to indicate statistical significance.

\section{Results}

\section{HAEMODYNAMIC EFFECTS OF CONTRAST INJECTION}

The haemodynamic changes in seven patients after left ventriculography using $45 \mathrm{ml}$ of Hexabrix (May and Baker) who received no felodipine were minor. Heart rate was increased by $6 \%$ and $5 \%$ at 10 and 20 minutes respectively, mean pulmonary pressure was increased by $10 \%$ at 20 minutes, and left ventricular $\mathrm{dP} / \mathrm{dt}^{-1}$ was increased by $5 \%$ at 20 minutes ( $\mathrm{p}<$ 0.05 in each case). No significant changes were observed at 30 minutes.

\section{PLASMA CONCENTRATIONS}

The Figure shows the plasma concentrations of felodipine. After an oral dose of $0.075 \mathrm{mg} / \mathrm{kg}$, plasma concentrations reached $16.4(3.5) \mathrm{nmol} / \mathrm{l}$ at 30 minutes and fell to $12.4(2.3) \mathrm{nmol} / \mathrm{l}$ after the second angiogram.

HEART RATE AND CARDIAC OUTPUT

During sinus rhythm, felodipine significantly increased heart rate from 55 (3) beats/min to 64 (3) beats/min and cardiac index from $2.3(0.1) \mathrm{l} / \mathrm{min}$ per $\mathrm{m}^{2}$ to $3.0(0.1) \mathrm{l} / \mathrm{min}$ per $\mathrm{m}^{2}$ ( $\mathrm{p}<0.01$ in each case). Felodipine increased cardiac index from $2.6(0.2)$ $1 / \min$ per $\mathrm{m}^{2}$ to $3.4(0.2) \mathrm{l} / \mathrm{min}$ per $\mathrm{m}^{2}(\mathrm{p}<0.01)$ during right atrial pacing. Although cardiac index was significantly increased by right atrial pacing before treatment the percentage increase produced by felodipine was identical in both conditions.

\section{BLOOD PRESSURES}

Felodipine produced small but significant reductions in arterial pressure during sinus rhythm and during atrial pacing. The extent of the change was more pronounced during atrial pacing than during sinus rhythm - that is, mean arterial pressure was reduced by $9.6 \%$ during atrial pacing compared with $6.6 \%$ during sinus rhythm (Tables 1 and 2). Felodipine increased pulmonary pressure during sinus rhythm and during pacing, the effect being more pronounced during sinus rhythm - that is, mean pulmonary pressure was increased by $30 \%$ compared with $18 \%$ during pacing (Tables 1 and 2). Neither pulmonary nor systemic pressure was significantly altered by pacing alone. Felodipine produced a small increase in left ventricular end diastolic pressure during sinus rhythm and during atrial pacing, but in neither instance was it statistically significant.

\section{PULMONARY AND SYSTEMIC VASCULAR}

RESISTANCE

Felodipine appreciably reduced systemic vascular resistance but had less effect on pulmonary vascular

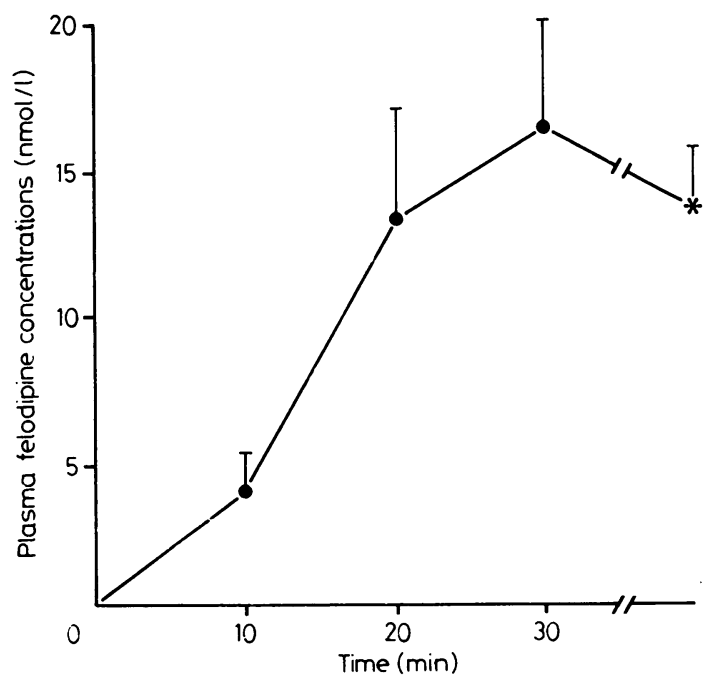

Figure Plasma concentrations of felodipine after oral administration of $0.075 \mathrm{mg} / \mathrm{kg}$. ${ }^{\star}$ After second left ventricular angiogram. Values are mean (SE). 
Table 1 Effect of felodipine on haemodymamic indices during sinus rhythm. Values are mean (SE)

\begin{tabular}{|c|c|c|c|c|}
\hline & Control & Felodipine & $\%$ Change & $p$ value \\
\hline Heart rate (beats/min) & $55(3)$ & $64(3)$ & +16.4 & 0.001 \\
\hline $\begin{array}{l}\text { Systolic } \\
\text { Diastolic } \\
\text { Mean }\end{array}$ & $\begin{array}{l}133(6) \\
63(3) \\
91(4)\end{array}$ & $\begin{array}{l}127(7) \\
58(4) \\
85(6)\end{array}$ & $\begin{array}{l}-4.5 \\
-7.9 \\
-6.6\end{array}$ & $\begin{array}{l}\text { NS } \\
0.05 \\
\text { NS }\end{array}$ \\
\hline $\begin{array}{l}\text { Pulmonary artery pressure (mm Hg): } \\
\text { Systolic } \\
\text { Diastolic } \\
\text { Mean }\end{array}$ & $\begin{array}{l}20.2(1.6) \\
4.9(1.0) \\
11 \cdot 1(1.4)\end{array}$ & $\begin{array}{l}24.4(1.7) \\
6.5(0.9) \\
14.5(1.5)\end{array}$ & $\begin{array}{l}+20.8 \\
+32.6 \\
+30.3\end{array}$ & $\begin{array}{l}0.005 \\
\text { NS } \\
0.01\end{array}$ \\
\hline $\begin{array}{l}\text { pressure }(\mathrm{mm} \mathrm{Hg}) \\
\text { Cardiac index }\left(\mathrm{l} / \mathrm{min} / \mathrm{m}^{2}\right) \\
\text { Vascular resistance }\left(\mathrm{dyn} \mathrm{s} \mathrm{cm}^{-5}\right)\end{array}$ & $\begin{array}{l}6.1(1.3) \\
2.3(0.1)\end{array}$ & $\begin{array}{l}7.7(1.3) \\
3.0(0.1)\end{array}$ & $\begin{array}{l}+26.9 \\
+29.6\end{array}$ & $\begin{array}{l}\text { NS } \\
0.001\end{array}$ \\
\hline $\begin{array}{l}\text { Systemic } \\
\text { Pulmonary } \\
\text { Peak dP/dt }\left(\mathrm{mm} \mathrm{Hg}^{\mathrm{H} / \mathrm{s})}\right. \\
\text { Peak dP/dt } \mathrm{P}^{-1}\left(\mathrm{~s}^{-1}\right)\end{array}$ & $\begin{array}{l}1603(72) \\
199.6(28) \\
1410(139) \\
28.0(3 \cdot 1)\end{array}$ & $\begin{array}{l}1165(78) \\
197(20) \\
1445(138) \\
27.9(3.0)\end{array}$ & $\begin{array}{l}-27 \cdot 3 \\
-1.3 \\
+2.5 \\
-0.6\end{array}$ & $\begin{array}{l}0.001 \\
\text { NS } \\
\text { NS } \\
\text { NS }\end{array}$ \\
\hline
\end{tabular}

resistance. Thus systemic vascular resistance was reduced by $30 \%$ during pacing $(\mathrm{p}<0.01)$ and by $27.3 \%$ during sinus rhythm $(\mathrm{p}<0.01)$ (Tables 1 and 2). In contrast, pulmonary vascular resistance was reduced by $11 \%$ during pacing and by $1.3 \%$ during sinus rhythm, and neither was statistically significant.

\section{INDICES OF LEFT VENTRICULAR FUNCTION}

Increasing heart rate by atrial pacing produced a significant increase in left ventricular $\mathrm{dP} / \mathrm{dt}$ and $\mathrm{dP} / \mathrm{dt}^{-1}$ before (18\% and $22 \%$ respectively) and after (13\% and $21 \%$ respectively) the administration of felodipine. Felodipine had no effect on these isovolumic indices of left ventricular function during sinus rhythm or during atrial pacing. In contrast ejection fraction, stroke volume, and mean velocity of circumferential fibre shortening were substantially increased $(13 \%, 8 \%$, and $19 \%$ respectively) at 30 minutes, although these changes did not reach statistical significance.

\section{Discussion}

The results confirm that felodipine is a potent dilator of systemic arterioles producing a significant reduction in systemic vascular resistance and a significant increase in cardiac index in a dose which had no effect on left ventricular peak $\mathrm{dP} / \mathrm{dt}$ or peak $\mathrm{dP} / \mathrm{dt} \mathrm{P}^{-1}$. Haemodynamic effects of the initial injection of contrast material can be excluded since no significant effects were detectable 30 minutes later. The dosage of felodipine used appears to have little effect on pulmonary arterioles, there being no significant change in pulmonary vascular resistance. During sinus rhythm felodipine produced a small but significant increase in heart rate despite concurrent beta adrenoreceptor blockade. There is no evidence that felodipine has a direct positive chronotropic action on the heart. The dose of atenolol used was high, and the low initial heart rates suggest that indeed substantial beta adrenoreceptor blockade was present. The small

Table 2 Effect of felodipine on haemodynamic indices during right atrial pacing ( 100 beats/min). Values are mean (SE)

\begin{tabular}{|c|c|c|c|c|}
\hline & Control & Felodipine & $\%$ change & $p$ value \\
\hline $\begin{array}{l}\text { Femoral artery pressure }(\mathrm{mm} \mathrm{Hg}) \text { : } \\
\text { Systolic } \\
\text { Diastolic } \\
\text { Mean } \\
\text { Pug }\end{array}$ & $\begin{array}{l}135(8) \\
78(4) \\
95(5)\end{array}$ & $\begin{array}{l}125(9) \\
66(4) \\
89(6)\end{array}$ & $\begin{array}{l}-6 \cdot 8 \\
-14.8 \\
-9.6\end{array}$ & $\begin{array}{l}0.05 \\
0.001 \\
0.001\end{array}$ \\
\hline $\begin{array}{l}\text { Pulmonary artery pressure }(\mathrm{mm} \mathrm{Hg}) \text { : } \\
\text { Systolic } \\
\text { Diastolic } \\
\text { Mean }\end{array}$ & $\begin{array}{l}19.8(2.3) \\
6.9(1.0) \\
12.4(1.9)\end{array}$ & $\begin{array}{l}22.3(1.8) \\
7.6(1 \cdot 1) \\
14.6(1.9)\end{array}$ & $\begin{array}{l}+12 \cdot 4 \\
+9 \cdot 3 \\
+17 \cdot 7\end{array}$ & $\begin{array}{l}\text { NS } \\
\text { NS } \\
\text { NS }\end{array}$ \\
\hline $\begin{array}{l}\text { Left ventricular end diastolic } \\
\text { pressure }(\mathrm{mmHg}) \\
\text { Cardiac index }\left(1 / \mathrm{min} / \mathrm{m}^{2}\right)\end{array}$ & $\begin{array}{l}5.6(1.6) \\
2.6(0.2)\end{array}$ & $\begin{array}{l}7 \cdot 1(1 \cdot 2) \\
3 \cdot 4(0 \cdot 2)\end{array}$ & $\begin{array}{l}+27 \cdot 7 \\
+29.6\end{array}$ & $\begin{array}{l}\text { NS } \\
0.001\end{array}$ \\
\hline $\begin{array}{l}\text { Vascular resistance }\left(\text { dyn } \mathrm{s} \mathrm{cm}^{-5}\right) \text { : } \\
\text { Systemic } \\
\text { Pulmonary } \\
\text { Stroke volume }(\mathrm{ml}) \\
\text { Ejection fraction } \\
\text { Velocity of circumferential }\end{array}$ & $\begin{array}{l}1537(88) \\
198(33) \\
72.8(7.0) \\
0.49(0.04)\end{array}$ & $\begin{array}{l}1075(88) \\
176(24) \\
82.1(10.8) \\
0.53(0.05)\end{array}$ & $\begin{array}{l}-30 \\
-11 \cdot 1 \\
+12 \cdot 8 \\
+8 \cdot 2\end{array}$ & $\begin{array}{l}0.001 \\
\text { NS } \\
\text { NS } \\
\text { NS }\end{array}$ \\
\hline $\begin{array}{l}\text { fibre shortening (circ/s) } \\
\text { Peak dP/dt }(\mathrm{mm} \mathrm{Hg} / \mathrm{s}) \\
\text { Peak dP/dt } \mathrm{P}-1\left(\mathrm{~s}^{-1}\right)\end{array}$ & $\begin{array}{l}1.0(0.07) \\
1660(158) \\
34.2(3.0)\end{array}$ & $\begin{array}{l}1.19(0.11) \\
1630(141) \\
33.8(2 \cdot 7)\end{array}$ & $\begin{array}{l}+19 \\
-1.8 \\
-1.3\end{array}$ & $\begin{array}{l}\text { NS } \\
\text { NS } \\
\text { NS }\end{array}$ \\
\hline
\end{tabular}


increase in heart rate may therefore have possibly been due to a reduction in parasympathetic stimulation. Felodipine reduced arterial pressure; however, this was greater during atrial pacing than during sinus rhythm suggesting that the increase in heart rate induced by felodipine tended to offset its hypotensive action. The reduction in diastolic arterial pressure was greater than that for systolic pressure, reflecting the primary action of the drug - that is, arteriolar dilatation. Pulmonary artery pressure was increased by felodipine, this effect being more pronounced during sinus rhythm. This is likely to be due to the increase in cardiac output in the absence of any change in pulmonary vascular resistance. These peripheral haemodynamic changes are similar to previous findings of a non-invasive study ${ }^{3}$ and to the haemodynamic effects of nifedipine. ${ }^{45}$

The increase in left ventricular $\mathrm{dP} / \mathrm{dt}$ and $\mathrm{dP} / \mathrm{dt}^{-1}$ observed with increasing heart rate confirms their value as useful indices of inotropic state in the present study. The absence of any change in response to felodipine indicates that at the dose used the drug does not depress myocardial function. Previous studies with nifedipine, in which heart rate and reflex sympathetic activity were not controlled, have shown increases in left ventricular $\mathrm{dP} / \mathrm{dt}$ and $\mathrm{dP} / \mathrm{dt}^{-16^{-8}}$ despite evidence to the contrary in vitro. ${ }^{11}$ This discrepancy can be explained by secondary increases in heart rate and sympathetic activation in vivo, so that when heart rate and sympathetic activation were controlled $\mathrm{dP} / \mathrm{dt}$ and $\mathrm{dP} / \mathrm{dt} \mathrm{P}^{-1}$ were reduced. ${ }^{45}$ The increase in stroke volume, ejection fraction, and mean velocity circumferential fibre shortening in the present study can be explained by the reduction in systemic arteriolar resistance.

These studies confirm that felodipine is a potent dilator of systemic arterioles with relatively little effect on the pulmonary circulation or systemic veins. The dose used in the present study produced a pronounced fall in systemic vascular resistance with no detectable effect on myocardial performance. This suggests that the drug is highly selective for smooth muscle and that it is likely to be a useful vasodilator for the treatment of cardiac failure or hypertension associated with myocardial damage.

\section{References}

1 Ljung B. Vascular versus myocardial selectivity in vitro of $\mathrm{H} 154 / 82$ a new dihydropyridine. Blood Vessels 1980; 17: 154 .

2 Boström S-L, Ljung B, Mårdh SF, Forsew S, Thulin E. Interaction of the antihypertensive drug felodipine with calmodulin. Nature 1981; 292: 777-8

3 Johnsson G, Murray G, Tweddel A, Hutton I. Haemodynamic effects of a new vasodilator drug, felodipine, in healthy subjects. Eur $\mathcal{7}$ Clin Pharmacol 1983; 24: 49-53.

4 Joshi PI, Dalal JJ, Ruttley MSJ, Sheridan DJ, Henderson $\mathrm{AH}$. Nifedipine and left ventricular function in beta blocked patients. Br Heart $\mathcal{F}$ 1981; 45: 457-9.

5 Rowland E, Razis P, Sugrue D, Krikler DM. Acute and chronic haemodynamic and electrophysiological effects of nifedipine in patients receiving atenolol. Br Heart $\mathcal{f}$ 1983; 50: 383-9.

6 D'Oliveira J, Ruiz Caderow N, Garcilazo E, Patricio J, Tewreyro E. Haemodynamic changes after a single dose of nifedipine (Adalat). In: Jatene AD, Lichtlen PR, eds. New therapy of ischamic heart disease: third international Adalat symposium. Amsterdam and Oxford: Excerpta Medica, 1976: 50-4 (International Congress Series; No 388).

7 Van den Brand M, Remine WJ, Meester GT Tiggerlaar-de Widt I, de Ruiter R, Hugenholtz PG. Changes in left and right ventricular haemodynamics in angina pectoris patients following Adalat administration. In: Jatene AD, Lichtlen PR, eds. New therapy of ischemic heart disease: third international Adalat symposium. Amsterdam and Oxford: Excerpta Medica, 1976: 69-75 (International Congress Series; No 388).

8 Peigas L, Paes Neto F, Konstadinidis T, de Megalhaes HM, de Souza JEMR, Jatene AD. Haemodynamic evaluation of a new antianginal drug: nifedipine. In: Jatene AD, Lichtlen PR, eds. New therapy of ischemic heart disease: third intermational Adalat symposium. Amsterdam and Oxford: Excerpta Medica, 1976: 76-82 (International Congress Series; No 388).

9 Kasser IS, Kennedy JW. Measurement of left ventricular volumes in man by single plane cineangiocardiography. Invest Radiol 1969; 4: 83-90.

10 Karliner JS, Gault JH, Eckberg D, Mullins CB, Ross J $\mathrm{Jr}$. Mean velocity of fiber shortening. A simplified measure of left ventricular myocardial contractility. Circulation 1971; 44: 323-33.

11 Fleckenstein A. On the basic pharmacological mechanism of nifedipine and its relations to therapeutic efficacy. In: Jatene AD, Lichtlen PR, eds. New therapy of ischemic heart disease: third international Adalat symposium. Amsterdam and Oxford: Excerpta Medica, 1976: 1-13 (International Congress Series; No 388). 